\title{
CORRECTION
}

\section{Correction to: A solution to PET brain motion artefact}

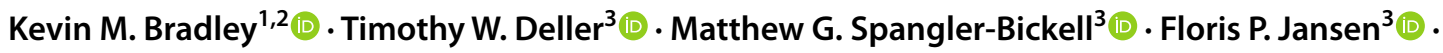 \\ Daniel R. McGowan ${ }^{1,4}$
}

Published online: 14 June 2021

(c) Springer-Verlag GmbH Germany, part of Springer Nature 2021

\section{Correction to: Journal of Neurology}

https://doi.org/10.1007/s00415-021-10632-4

The original version of this article unfortunately contained a mistake. Figure 1 was wrong.

The corrected Fig. 1 is given in the following page

The original article has been corrected.

Publisher's Note Springer Nature remains neutral with regard to jurisdictional claims in published maps and institutional affiliations.

The original article can be found online at https://doi.org/10.1007/ s00415-021-10632-4.

\section{Daniel R. McGowan}

Daniel.mcgowan@oncology.ox.ac.uk

1 Oxford University Hospitals NHS FT, Oxford, UK

2 Wales Research and Diagnostic PET Imaging Centre, University Hospital of Wales, Cardiff, UK

3 GE Healthcare, Waukesha, USA

4 Department of Oncology, University of Oxford, Oxford, UK 
a

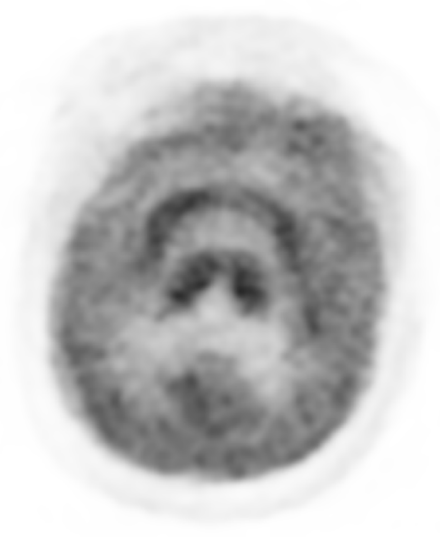

C

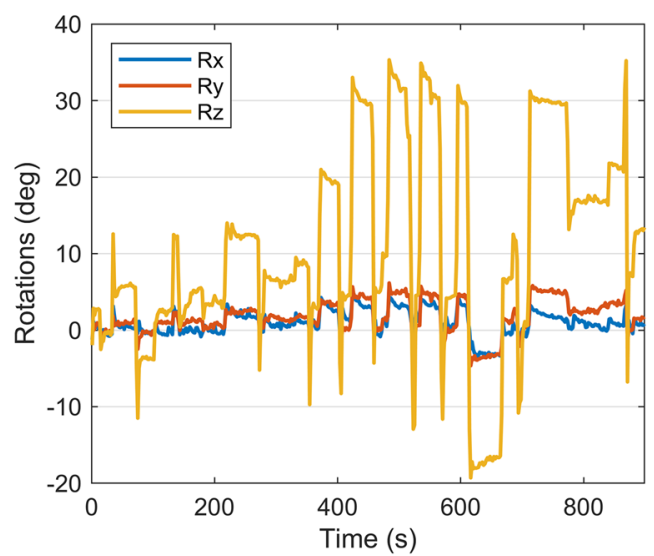

Fig. $1{ }^{18}$ F-Fluorodeoxyglucose, axial PET image at the level of the basal ganglia with significant blurring due to movement (a). Corresponding axial PET image, corrected for motion (b), all other recon-

b

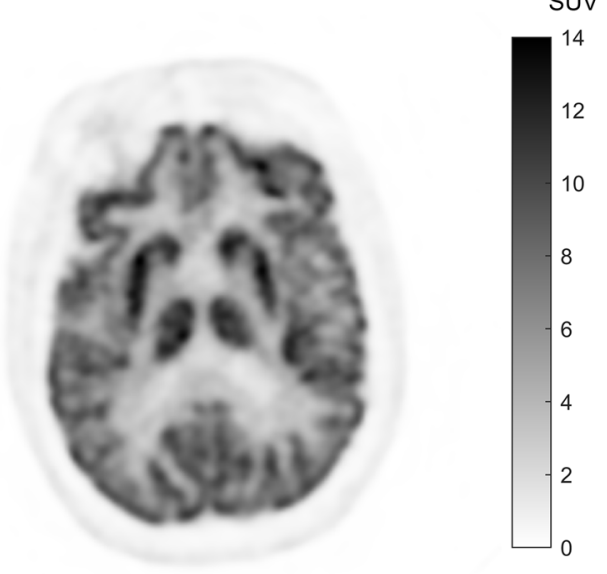

d

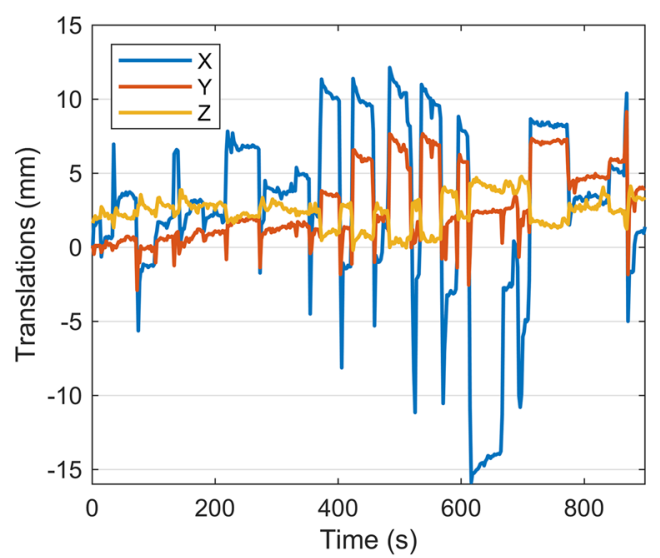

struction factors unchanged. Graphs illustrating the baseline rotation (c) and translation (d) versus time, which were subsequently corrected 